\title{
Pregnancy and infant loss: a survey of families' experiences in Ontario Canada
}

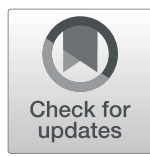

Jo Watson ${ }^{1,2^{*}}$ (D) Anne Simmonds ${ }^{2}$, Michelle La Fontaine ${ }^{1}$ and Megan E. Fockler ${ }^{1,2}$

\begin{abstract}
Background: Pregnancy and infant loss has a pervasive impact on families, health systems, and communities. During and after loss, compassionate, individualized, and skilled support from professionals and organizations is important, but often lacking. Historically, little has been known about how families in Ontario access existing care and supports around the time of their loss and their experiences of receiving such care.

Methods: An online cross-sectional survey, including both closed-ended multiple choice questions and one openended question, was completed by 596 people in Ontario, Canada relating to their experiences of care and support following pregnancy loss and infant death. Quantitative data were analyzed descriptively using frequency distributions. Responses to the one open-ended question were thematically analyzed using a qualitative inductive approach.
\end{abstract}

Results: The majority of families told us that around the time of their loss, they felt they were not adequately informed, supported and cared for by healthcare professionals, and that their healthcare provider lacked the skills needed to care for them. Almost half of respondents reported experiencing stigma from providers, exacerbating their experience of loss. Positive encounters with care providers were marked by timely, individualized, and compassionate care. Families indicated that improvements in care could be made by providing information and explanations, discharge and followup instructions, and through discussions about available supports.

Conclusions: Healthcare professionals can make a positive difference in how loss is experienced and in overall wellbeing by recognizing the impact of the loss, minimizing uncertainty and isolation, and by thoughtfully working within physical environments often not designed for the experience of loss. Ongoing supports are needed and should be tailored to parents' changing needs. Prioritizing access to specialized education for professionals providing services and care to this population may help to reduce the stigma experienced by bereaved families.

Keywords: Perinatal loss, Stigma, Miscarriage, Stillbirth, Infant death, Pregnancy loss, Neonatal death, Perinatal care, Ontario, Healthcare professionals

\section{Background}

Pregnancy and infant loss has a pervasive impact on childbearing families, communities, and health systems. After a loss, families may experience intense grief, sadness, shame, guilt, regret, anger, and stigma, both in the short and long-term [1-12]. They may also experience other life-altering changes, such as changes to relationships, employment, mental health, psychosocial needs in subsequent

\footnotetext{
* Correspondence: jo.watson@sunnybrook.ca

'Pregnancy and Infant Loss (PAIL) Network, Women and Babies Program, Sunnybrook Health Sciences Centre, 2075 Bayview Avenue, Toronto, Ontario, Canada

${ }^{2}$ Lawrence S. Bloomberg Faculty of Nursing, University of Toronto, Toronto, Ontario, Canada
}

pregnancies, and personal core and spiritual beliefs [2-4, 10, 13-19]. Many families experience isolation from and changes to their normal support networks, [1, 3, 5, 20-22] often in relation to insensitive comments from others [5, 23, 24]. Families commonly report that their loss is unacknowledged or minimized by their families, social circles, healthcare providers and community $[1,2,4-7,17$, 19, 25-29]. Prior to this survey, little was known about how families in Ontario accessed and experienced existing perinatal bereavement care and supports, and their thoughts on system gaps and needed improvements.

Ontario is a Canadian province with over 13.5 million residents and approximately 141,000 births annually 
[30]. Ontario has universal healthcare meaning residents who qualify can access healthcare services in the community and hospital, including primary care, obstetrical, and emergency health services. However, access can be limited by a number of factors including socioeconomic location, gender, immigration status, and geographical location [31]. In Ontario, early pregnancy care (until approximately 12 weeks gestational age) is often provided by a person's primary care provider (family physician or nurse practitioner), midwives, or in the case of complications, emergency care providers. Family physicians, midwives, nurse practitioners, and obstetricians provide primary maternity care and postpartum follow-up to approximately six weeks post-birth. After this timeframe, health and medical care is often resumed by a person's primary care provider. Ongoing infant and child healthcare is mainly provided by family physicians, nurse practitioners, and pediatricians.

\section{Loss statistics in Ontario}

Tens of thousands of families in Ontario are impacted by pregnancy and infant loss each year. In Ontario, between April 1, 2016 and March 31, 2017, there were approximately 38,665 recorded visits to emergency departments in Ontario related to pregnancy losses (under 20 weeks gestational age) and their associated complications [32], representing approximately 106 visits to emergency departments every day, or one family every $14 \mathrm{~min}$. Between 2012 and 2016, there were 6904 reported stillbirths [30] and 3283 reported infant deaths in Ontario [33], meaning that one family is impacted by stillbirth every six hours, and one family is impacted by infant death every $13 \mathrm{~h}$ in Ontario.

\section{Bill 141 and PAIL network}

In December 2015, Bill 141: The Pregnancy and Infant Loss Awareness, Research, and Care Act was enacted by the Legislative Assembly of the Province of Ontario into law [34]. Bill 141 is the first time any province in Canada has succeeded in passing legislation that mandates research and analysis on pregnancy loss and infant death that assists those who experience such loss and that informs the establishment or expansion of programs related to such loss. Bill 141 was intentionally broad in mandate, focusing program analysis and expansion related to all experiences of pregnancy and infant loss, regardless of gestational age. This groundbreaking piece of legislation has allowed for the issues surrounding pregnancy and infant loss to come to the forefront and begin receiving the attention and government support so desperately needed to evoke change.

As a result of Bill 141, the Pregnancy and Infant Loss (PAIL) Network at Sunnybrook Health Sciences Centre in Toronto, Ontario, Canada, has the funded responsibility, via the Ministry of Health and Long-Term Care, to provide free peer support services to bereaved parents and their families across Ontario, regardless of the nature of their loss, and has as their mandate the improvement and expansion of support services in Ontario. The purpose of this survey was to collect and report aggregate data on people's experiences of perinatal bereavement supports in Ontario, and to inform the development of a strategic plan by PAIL Network to improve and expand services provided across Ontario, as well as training and support for healthcare and service professionals. The questions that guided our research study were:

"What are the experiences of parents at the time of pregnancy or infant loss with respect to available or needed supports?" and,

"How do families perceive the support provided by healthcare professionals at the time of their loss?"

The information gained from the survey identified practices for supporting people who experience pregnancy and infant loss. PAIL Network is committed to utilizing the voices of bereaved parents in the development of policy and programming, and providing resources and services to people in Ontario.

\section{Methods}

A cross-sectional online survey was conducted in order to gather data about people's experiences of the loss of a pregnancy or the death of an infant and their thoughts on service and system gaps in Ontario, Canada. Ethics approval was received from the Sunnybrook Health Sciences Centre Research Ethics Board (Approval Number: 443-2016). Contact information for PAIL Network was provided at the start and end of the survey in case participants became distressed in the process of completing the survey.

\section{Sample}

Using purposive sampling, people who lived in Ontario and had a pregnancy loss at any gestation of pregnancy (i.e. the person who carried the pregnancy or their intimate partner(s)), or who had experienced the death of an infant, were eligible to complete the survey about their experiences with the healthcare system and community supports at the time of the loss and during follow up. If participants had experienced more than one pregnancy or infant loss, they were asked to focus on only one loss when completing the survey. Participants were asked about the care and supports they received and to identify gaps or improvements needed. In order to fulfill PAIL Network's provincial mandate to better plan for the creation of needed supports in Ontario, 
participants were excluded if they did not live in Ontario at the time of their loss.

Advertisements inviting people to participate were placed on the public Bill 141 Facebook page and PAIL Network website, with a link to the survey, information about the purpose of the study, and contact details for the primary investigator and the chair of the research ethics board for questions related to participation. No identifiable information was collected from respondents. Informed consent was implied through independent completion and submission of the survey. The survey was available for completion online for two months during January and February 2017.

\section{Survey}

The anonymous, web-based survey was designed following a review of the perinatal loss literature and discussed amongst the researchers, which included clinicians and a person with lived experience of pregnancy loss. The draft survey was initially reviewed by a person with expertise in online survey development, and minor revisions were made based on her feedback. The survey was then piloted with a group of women $(n=5)$ with lived experience of loss (miscarriage, stillbirth, neonatal death, infant death) accessed through Sunnybrook Health Sciences Centre. These bereaved parents were asked about their thoughts on the length, content, ease of online completion, and wording of the survey and whether they were able to express what they wanted to express. Minor survey revisions were made based on their feedback. The final survey included 59 closed-ended multiple choice questions (Likert, partial, and unordered) that focused on care and supports discussed or accessed both at and after the time of the loss, as well as current gaps in care and services and the experience of a pregnancy after loss. The format of the final survey included skip-logic such that respondents were directed through different paths based on their responses. In addition, one free-text question was included to allow respondents to express any thoughts or experiences considered important that they were unable to express in the rest of the survey and to further describe their experiences in their own terms. Allowing respondents to describe their experiences in their own terms can illuminate elements of a complex issue and can also function to redress the power imbalance between researchers and participants by giving voice to the respondents' opinions in a way that is unconstrained by the researchers' agenda $[35,36]$.

\section{Analysis}

Descriptive statistics were used to analyze the multiple-choice survey questions. The responses were summarized numerically by Survey Monkey, and then placed in tabular format [37]. For the open-ended question, a qualitative inductive approach using thematic analysis was used as a means of condensing raw textual data into categories and themes to attain a more indepth understanding of the experiences described within the participant responses [38]. Thematic analysis is seen as a flexible approach for summarizing key features of a large data set and for examining the perspectives of different research participants, highlighting similarities and differences, and generating insights [39]. Thematic analysis was undertaken through a systematic process that included close reading of the raw data, coding, and developing themes related to families' experience of loss. Data extracts for each theme were considered to determine whether the themes accurately reflected the voices of participants. Peer debriefing and reflexive writing throughout the process were employed to deepen engagement with the data and establish credibility [39].

\section{Results}

In total, six-hundred and seven people responded to the survey between January and February 2017. Respondents were removed from analysis if the loss took place outside Ontario $(n=5)$ or they did not progress past question $3(n=6)$, leaving 596 responses for further analysis. Out of the 596 respondents, 79 did not complete the entire survey; 21 responded to less than $25 \%$ of the survey questions. If a respondent did not answer a question, they were not counted in the denominator for calculations. For participants who answered the question about relation to the loss or losses $(n=515), 501$ had experienced the loss themselves, while 14 reported that their partner had the loss or losses. In total, 269 (52\%) respondents completed the open-ended question. Within the total responses, 210 made specific reference to their healthcare provider, and 174 of these references highlighted some negative aspect of their care.

\section{Demographics}

The characteristics of survey respondents are summarized in Table 1. The majority of respondents were female, between 30 and 44 years of age, and White although some people identified as Arab, Black, Chinese, Filipino, or Japanese, First Nations or Metis, Latin American, South, Southeast, or West Asian, 'other', or Aboriginal or visible minority not included elsewhere ( $n$ $=73[13.6 \%])$. Participants mostly spoke English as their primary language, although a small number identified French, Aboriginal language, Chinese (Cantonese), Portuguese, Punjabi, Russian, and Spanish as their primary language $(n=13[2.5 \%])$. For participants who responded to the question asking about their gender $(n=515), 13$ people identified as male, 495 identified as female, and 7 identified as other. Annual household incomes ranged from less than $\$ 5000$ to over $\$ 150,000$, with $45 \%$ of 
Table 1 Demographic characteristics of participants. ( $N=596$; some did not respond to all questions, some selected $>1$ ethnic groups)

\begin{tabular}{lll}
\hline Characteristic & & $\mathrm{n}(\%)$ \\
\hline Gender & Male & $13(2.52 \%)$ \\
& Female & $495(96.12 \%)$ \\
& Other & $7(1.36 \%)$ \\
Age & Under 30 & \\
& $30-39$ & $60(11.65 \%)$ \\
& $40-49$ & $354(68.74 \%)$ \\
Ethnic group & Over 50 & $86(16.70 \%)$ \\
Primary language & White & $15(2.91 \%)$ \\
& English & $452(87.77 \%)$ \\
Household Income & & $501(97.28 \%)$ \\
& Less than \$100,000 & \\
& Over \$100,000 & $220(42.72 \%)$ \\
& Prefer not to answer & $235(45.63 \%)$ \\
& & $60(11.65 \%)$ \\
\hline
\end{tabular}

respondents having annual household incomes greater than $\$ 100,000$. Eighty-eight percent of respondents had attended college or university.

\section{Timing of loss}

Six-hundred-and-seven initial respondents reported having experienced a total of 1625 losses, an average of three losses per respondent. Over half of these losses (883) occurred during the first trimester. We asked participants who had experienced more than one loss to respond to the full survey thinking about only one of their losses (Table 2). Following Canadian definitions, timing of loss options to select included:

- Miscarriage (pregnancy loss under 20 weeks gestational age)

- Stillbirth (loss over 20 weeks gestational age)

- Neonatal death (death of baby within 28 days of life)

- Infant death (death of baby after 28 days of life, but within one year)

- Pregnancy termination for medical or other reasons

Fifty-five percent of respondents thought about a miscarriage (or other pregnancy loss under 20 weeks gestational age) when they completed the survey $(n=330)$. Fifty percent of the losses remembered by the respondents took place one to five years ago. Other responses included in the last three months (7\%) and more than ten years ago (10\%).

Care providers at the time of the loss are summarized in Table 3. Individuals who were already receiving antenatal care were receiving this care from family physicians, obstetricians or maternal fetal medicine specialists, nurse practitioners, or midwives. Twelve percent of respondents (or their partners) were not yet registered with an obstetrical provider for pregnancy care at the time of their loss.

At the time of their loss, participants received care from their primary care provider, Emergency Medical Services (EMS), or in a birthing unit or the emergency department, as well as walk-in clinics, early pregnancy loss clinics, operating rooms, perinatal hospice programs, and fertility clinics. For this question, respondents were able to select all applicable care provider options. Totals indicated that many people accessed care

Table 2 Timing of loss $(N=596)$

n (\%)

\begin{tabular}{|c|c|c|}
\hline \multicolumn{3}{|l|}{ Timing of loss } \\
\hline & Miscarriage or other pregnancy loss under 20 weeks gestational age & $330(55.36 \%)$ \\
\hline & Stillbirth & $162(27.18 \%)$ \\
\hline & Neonatal death & $47(7.89 \%)$ \\
\hline & Infant death & $18(3.02 \%)$ \\
\hline & Pregnancy termination for medical or other reasons & $39(6.55 \%)$ \\
\hline \multicolumn{3}{|c|}{ Timing of experience } \\
\hline & Less than 3 months ago & $44(7.38 \%)$ \\
\hline & $3-6$ months ago & $41(6.88 \%)$ \\
\hline & $6-12$ months ago & $65(10.91 \%)$ \\
\hline & $1-5$ years ago & $298(50.00 \%)$ \\
\hline & $5-10$ years ago & $86(14.43 \%)$ \\
\hline & More than 10 years ago & $62(10.40 \%)$ \\
\hline
\end{tabular}


Table 3 Care providers $(N=596)$

Receiving pregnancy care at the time of loss

From a Midwife
From a Family Physician
From a Nurse Practitioner
From an Obstetrician
From a High Risk Physician (Maternal Fetal Medicine Physician)
Not receiving pregnancy care at the time

Medical attention for participant or partner at the time of loss because of loss

\begin{tabular}{lr} 
From Primary Care Provider & $189(31.71 \%)$ \\
From Primary Pregnancy Care Provider & $198(33.22 \%)$ \\
From Emergency Response & $33(5.54 \%)$ \\
From Emergency Department & $215(36.07 \%)$ \\
From a Hospital Labour/Delivery Unit & $210(35.23 \%)$ \\
From an Early Pregnancy Loss Clinic & $27(4.53 \%)$ \\
From a Fertility Clinic & $31(5.20 \%)$ \\
From a Neonatal Intensive Care Unit or Pediatric Unit & $0(0.00 \%)$ \\
From a Palliative Care Team & $0(0.00 \%)$ \\
Did not receive medical attention or care at time of loss & $30(5.03 \%)$ \\
Other & $42(7.05 \%)$ \\
\hline
\end{tabular}

at multiple points and from multiple professionals during their loss. Five percent indicated that they did not seek any medical attention at the time of their loss.

Time of loss: care received from healthcare professionals Evaluation of the care received at the time of the loss is included in Table 4. Of the participants who stated that they received care from a healthcare professional at the time of their loss, $47 \%$ of participants responded 'yes, definitely' when asked if they were treated with kindness and respect.

When asked if they were given the information and explanations they needed from healthcare providers, $28 \%$ responded 'yes, definitely'. When asked about feeling supported and cared for by healthcare providers, $35 \%$ of participants responded 'yes, definitely' and 31\% of the same participants responded 'yes, definitely' when asked if the healthcare providers had the skills needed to

Table 4 Evaluation \& experiences of care

\begin{tabular}{|c|c|c|}
\hline & Question, phrase, or option & n \% - options \\
\hline \multicolumn{3}{|l|}{ At the time of loss } \\
\hline & Treated with kindness \& respect & $266(47 \%)$ - Yes, definitely \\
\hline & Given information & 157 (28\%) - Yes, definitely \\
\hline & Felt supported & 195 (35\%) - Yes, definitely \\
\hline & HCP had skills needed & 175 (31\%) - Yes, definitely \\
\hline & Not given any discharge or follow up instructions & $129(23 \%)$ - selected this option \\
\hline & Experienced stigma & 136 (24\%) \& 139 (25\%) - Yes, definitely \& Yes, somewhat \\
\hline \multicolumn{3}{|l|}{ Follow-up care } \\
\hline & Offered appointment (regardless of whether attended) & $320(55 \%)$ - selected this option \\
\hline & Treated with kindness and respect & $261(69 \%)$ - Yes, definitely \\
\hline & Felt supported \& cared for & $230(60 \%)$ - Yes, definitely \\
\hline & HCP had skills needed & 194 (51\%) - Yes, definitely \\
\hline & Experienced stigma & $31(8 \%)$ \& $71(19 \%)$ - Yes, definitely \& Yes, somewhat \\
\hline
\end{tabular}


respond to their needs. When asked about being given discharge or follow-up instructions from healthcare providers, $23 \%$ indicated they were given no instruction, while $8 \%$ indicated they did not remember if they were or not. When people received discharge or follow-up instructions, verbal (55\%) and written instructions (29\%) were most common.

When asked if they experienced stigma from healthcare professionals, defined in our study as insensitive comments about how you should feel, grieve, or experience the loss that you did not agree with, or care that did not recognize the significance of your loss or your need for support', $[40,41] 49 \%$ of participants responded 'yes'.

\section{Follow-up appointment}

Evaluation of the care received at the time of the loss is included in Table 4 . The majority of participants (67\%) had a follow-up appointment with a healthcare professional after their loss (they either were offered one or made one themselves). Fifty-one percent of those who attended a follow-up appointment were offered an appointment at or around the time of their loss, while the other $16 \%$ made the follow-up appointment themselves. At the follow-up appointment, $69 \%$ responded 'yes, definitely' when asked if they were treated with kindness and respect, and 60\% responded 'yes, definitely' when asked if they felt supported and cared for by the healthcare provider. Slightly more than half $(51 \%)$ of all participants who had a follow-up appointment responded 'yes, definitely' when asked if the healthcare provider had the skills needed to respond to their needs. At the follow-up appointment, $27 \%$ of the total participants reported experiencing stigma about their loss from the healthcare provider.

\section{Sources of support}

The most common sources of support at the time of the loss included partners (82\%), friends (69\%), parents (63\%), and other family members (44\%). Employers (35\%) and co-workers (28\%), as well as online support (26\%) and other bereaved parents (25\%), were also listed as sources of support. When asked to choose their most important source of support, $43 \%$ of participants selected their partner. Healthcare professionals were reported as sources of support to families as well. These included family physicians (40\%), hospital nurses (33\%), obstetricians (33\%), and midwives (16\%). When asked about the type of support provided by a healthcare professional, the most common responses were medical or physical support (64\%), emotional support (55\%), and informational support (49\%).

Participants were asked about the types of formal and informal sources of support that they were told about around the time of their loss. Almost half of all respondents (45\%) were not told of any sources of support. The most common sources of support that participants were told about were written supports (24\%), PAIL Network support groups or local community peer support groups (21\% respectively), and professional counseling (20\%).

Sources and obstacles of support are presented in Table 5. Participants were asked if they accessed formal or organized supports around the time of their loss, and 58\% reported they had done so. The most common ways to access support included 'in person (64\%), 'Facebook' (45\%), 'internet or other loss support websites' (45\%), 'books or written resources' (45\%), 'phone' (26\%), or 'email' (18\%). In person support, books and written resources, and online support were most rated as 'very helpful' (45, 30, and 29\% respectively). Facebook, Twitter, other social media, and the internet, when combined, were the most helpful sources of support across all groups.

When asked about how easy it was to access support around the time of their loss, $6 \%$ of total respondents selected 'very easy' and 18\% selected 'very difficult'. The survey also asked participants about the obstacles they faced when trying to access formal or organized supports (Table 5). The most common obstacles included not being aware of resources or that there were no resources available.

\section{Support - changing needs over time}

Seventy-eight percent of participants indicated that over time, the type of support they needed changed. Reasons for this changing need, selected from an a priori list with an additional option for open text ('other' option), included relying more on themselves (36\%), needing more formal professional one-on-one support (33\%), and still needing support, but not as often as before (32\%). Thirty-one percent indicated that they relied more on family and friends for support over time. When asked about whether or not they were able to get the support they needed over time, $23 \%$ of total participants responded 'yes, definitely'.

\section{Peer support}

Participants who indicated that they accessed support around the time of their loss (58\% of total respondents) were then asked specifically if they accessed peer support. Peer support, defined as 'support provided by other bereaved parents', was accessed by $78 \%$ of these respondents (Table 5). Participants who responded 'yes' to accessing peer support were asked about what was useful or helpful about this type of support (Table 5). One percent indicated that peer support was not useful or helpful. When asked if there was anything that they did not like or found challenging about the peer support they accessed, the most common responses, selected from an a priori list with an additional option for open text ('other' option), were 'no' (35\%), 'location of group 
Table 5 Support

\begin{tabular}{|c|c|}
\hline Question, phrase, or option & $\%$ - options \\
\hline \multicolumn{2}{|l|}{ Support Accessed } \\
\hline Easy to access support & $22 \%$ - Very easy \& Somewhat easy \\
\hline Accessed support & $58 \%$ - selected this option \\
\hline Accessed peer support & $78 \%$ - selected this option \\
\hline Able to get needed support & $23 \%$ - Yes, definitely \\
\hline Need for support changed over time & $76 \%$ - selected this option \\
\hline How much support is in your community? & 15.5\% - More than enough \& Enough \\
\hline \multicolumn{2}{|l|}{ Obstacles faced } \\
\hline I didn't know what supports were available & $65 \%$ - selected this option \\
\hline No local supports available in my community & $33 \%$ - selected this option \\
\hline Stigma or silence about pregnancy and infant loss & $23 \%$ - selected this option \\
\hline Available supports did not meet my personal emotional needs & $20 \%$ - selected this option \\
\hline I was feeling unwell and unable to access supports at the time & $18 \%$ - selected this option \\
\hline \multicolumn{2}{|l|}{ Efficacy of peer support (Top 6 reasons) } \\
\hline Knowing that I was not the only person to have experienced pregnancy or infant loss & $89 \%$ - selected this option \\
\hline Being able to hear about other people's experiences with pregnancy or infant loss & $83 \%$ - selected this option \\
\hline Being able to talk openly about my loss experience & $78 \%$ - selected this option \\
\hline Being able to share my story with others who have experienced pregnancy or infant loss & $74 \%$ - selected this option \\
\hline I felt less alone or isolated & $71 \%$ - selected this option \\
\hline Being able to talk openly about my baby & $70 \%$ - selected this option \\
\hline
\end{tabular}

was not convenient' (18\%), 'not enough support for men' (16\%), 'other' (15\%), and 'timing of group was not convenient' $(13 \%)$.

\section{Community supports}

When asked about how much support was available for families experiencing pregnancy or infant loss in their local community, $84 \%$ of total respondents selected either 'not enough' or 'none'. Key areas of concern for participants for families experiencing loss in their communities, selected from an a priori list with an additional option for open text ('other' option), are listed in Table 6, and included reducing stigma and silence about perinatal loss, automatic referrals to bereavement or counseling supports, more public awareness about the frequency and impact of pregnancy and infant loss, and better follow-up by healthcare professionals.

\section{Thematic analysis}

Four themes were identified from qualitative analysis of the open-ended question: a) isolation and exclusion, b)

Table 6 Key areas of need or concern

\begin{tabular}{lc}
\hline Question, phrase, or option & $\%$ - options \\
\hline Top 10 areas & $69 \%$ - selected this option \\
Reducing stigma or silence about pregnancy and infant loss & $66 \%$ - selected this option \\
Automatic referral to bereavement or counseling supports for families after loss & $62 \%$ - selected this option \\
More public awareness or education about the frequency and impact of pregnancy and infant loss & $59 \%$ - selected this option \\
More public awareness or education about existing supports & $56 \%$ - selected this option \\
Better follow-up by healthcare providers for families after loss & $55 \%$ - selected this option \\
Better training for healthcare providers who care for families experiencing pregnancy and infant loss & $55 \%$ - selected this option \\
Early pregnancy loss clinic & $53 \%$ - selected this option \\
Availability of skilled and compassionate healthcare providers & $51 \%$ - selected this option \\
Better mental health supports & $51 \%$ - selected this option \\
More information in general about pregnancy and infant loss
\end{tabular}


recognizing and responding to loss, c) accessing information and supports, and d) making a difference.

\section{Isolation and exclusion}

Many respondents described isolation and exclusion as significant factors influencing their experience of loss, with one respondent explaining, "It just felt like once I wasn't pregnant anymore, I didn't matter to anyone." (Miscarriage/early loss) Stigma led to further isolation. One person reported that they "faced stigma and felt embarrassed like I should hide my losses and I was responsible." (Miscarriage/early loss, stillbirth) Another wrote that having waited to disclose the pregnancy only increased their sense of isolation and the stigma surrounding loss, noting, "We hadn't told anyone that we were expecting so suffered alone and in silence." (Miscarriage/early loss).

The uniqueness of the loss for each person meant that many felt unwelcome within some groups or that they did not belong, leading to feelings of exclusion and inability to access desired supports. As one person reported, "I made the mistake of attending an open loss group and was told by another group member that my loss wasn't the same as theirs because I could have another baby but she couldn't." (Miscarriage/early loss, stillbirth) Exclusion was also experienced by an adoptive mother, who explained, "I did not physically birth him. But he was mine. I felt like I couldn't go to any support groups. Like I wouldn't fit in." (Infant death) There was also a perceived gap in supports available for people who undergo fertility treatments after a loss. As one respondent explained, "a lot of fertility patients have suffered multiple miscarriages and receive fertility support but never deal with the actual emotions and trauma of the miscarriages." (Miscarriage/early loss, stillbirth).

Fathers and same gender families also experienced feelings of exclusion. The impact of the lack of support on relationships was evident in another person's comment that they were watching their husband "fade away" as he felt he had nobody to talk to. (Neonatal death) Heteronormativity exacerbated feelings of isolation for LGBTQ2S (lesbian, gay, bisexual, transgendered, queer, two-spirited) families, as noted by one respondent who said, "I often felt isolated because of how gendered the support groups are. There are many queer families suffering from pregnancy and infant loss and it seems there isn't a place for the partner". (Miscarriage/early loss, stillbirth) Partners also wished for a more inclusive approach to care. One father explained that,

"As a male, I understand that priority in pregnancy and baby losses is given to mom. However, I really hope that compassionate and integral family care can be offered to all family members. There is a lot of stress for fathers too (or same gender partners), who on top of having their own grief are expected to 'stay strong"'. (Miscarriage/early loss, stillbirth).

\section{Recognition and response to loss}

The difference in the meaning of the loss between families and healthcare professionals influenced recognition and response. This was evident in the terminology used and attempts to reframe the loss in technical terms. One person explained, "I was telling them about my baby, which I delivered at home, and was calcified, they interrupted me and called it a fetus." (Miscarriage/early loss). Another person reported that, "after telling me I was having a miscarriage my GP asking why I was crying...I said I wanted that baby....and then he said it was not a baby it was a fetus." (Miscarriage/early loss).

Comments from healthcare professionals such as, "many women go through this", "you can try again", and "it wasn't meant to be" (all miscarriage/early loss) had an impact on the respondents, reflecting a lack of compassion and recognition of the impact of the loss. Many respondents perceived that their devastating loss was treated like a routine event by healthcare professionals, with one respondent noting, "Doctors who see this tragedy every day, need to be reminded that this is a first for us." (Neonatal death). As another person explained, "The doctor who performed my $D \& C$ was very insensitive, treating my miscarriage as a normal, everyday event. It was the most tragic thing that ever happened to me". (Miscarriage/early loss).

The need for healthcare providers to attend to the power of language used at the time of loss was evident, as one respondent noted,

"During my second loss, I was under the care of a very insensitive [healthcare professional]. After that happened, I left her care because I couldn't see going back to her after that. She kept referring to my loss as a 'spontaneous abortion' which I'm sure is clinically correct, but even after I asked her to stop using the term she continued to do so. It made my appointments very painful mentally and I really dreaded them. Health care practitioners need education on how to speak to people who have been through loss with sensitivity." (Miscarriage/early loss).

The uncertainty of 'knowing' something was wrong, not being believed, and waiting for confirmation of the loss, along with lack of information, emotional support, and anticipatory guidance added to the distress experienced by the respondents. One person who had a termination at 23 weeks explained, "I wasn't prepared for a 
full blown labour ...we didn't know we'd have to arrange a funeral or what our baby would look like or what decisions we'd have to make...". Another noted, "We were told to anticipate "a heavy period", when in reality we were experiencing the labour and delivery of a small, dead, baby." (Miscarriage/early loss).

The environment of care shaped recognition and response to perinatal loss. Many people went to emergency rooms where they were not seen as urgent or important and where they perceived that healthcare professionals lacked the training, knowledge, and sensitivity to respond appropriately to their loss. As one person reported,

"The ER nurse told me 'Get control of yourself or I won't talk to you... If you want to see someone you'll have to wait.' I went into the ER bathroom and ended up miscarrying there. It was unbelievably awful...I felt judged, ignored, and discarded." (Miscarriage/early loss, medical termination of pregnancy).

Another person described her experience of miscarrying in the hallway of a hospital in a bedpan, explaining, "they left it on the floor and other nurses were saying 'ewww what's that'...then I heard them say 'throw it away'... my dearly loved child ... I cry as I think about it".

One person cited the importance of healthcare professionals' knowledge and awareness in ensuring recognition of loss and access to supports. When making the difficult decision to end a non-viable pregnancy early, one mother was told by a social worker that she was "not eligible" for the late loss group, only to find out later - after emailing the group facilitator - that they were welcome. Another person who experienced a loss at 14 weeks was advised that "statistically" this was not considered to be an infant loss. A respondent who experienced what was described as 'a chemical pregnancy' explained that these were not perceived as legitimate pregnancies and babies, noting, "There needs to be a certain level of compassion, understanding, and empathy when discussing these types of losses, particularly for those women who disclose the importance or sadness associated with the loss".

Respondents also described a lack of recognition in the workplace of the impact of perinatal loss. This was evident in the lack of policies to support work absence as well as insensitivity encountered from managers, colleagues, human resources, and insurance companies. They described being "harassed" for taking sick days (Miscarriage/early loss) and being told by their employers that they had been on leave "long enough." (Stillbirth) Many described highly unsupportive and uncompassionate workplaces and struggled to explain the significance of their loss in order to take time off. The financial consequences of stigma related to perinatal loss in the workplace were real. One person explained that they almost lost their home due to the severe depression that occurred after their bereavement leave. Another who applied for short term disability believed that this impacted future promotions while one person who was a contract worker was laid off upon their return and they were unable to pursue legal challenges due to their contract status.

\section{Accessing information and supports}

Responses indicated high variance in the services available, including knowledgeable caregivers and written material, further compounding the loss experience. A frequently cited concern of respondents was wishing they had had more support at the time of their loss, and guidance about what to do. As one person explained,

"We were so shocked we needed guidance on next steps and our options and we weren't thinking straight. I wish I was told I could take pictures of him, that I could bathe him, that I could have more time with him...now I am filled with regret that I didn't spend more time with him and take more pictures of him. I wish a doctor/nurse/social worker told me I could do this as I know I would have said yes if given the option". (Stillbirth).

The lasting impact of lack of access to this kind of support was also captured by one person who stated,

"I'm crying as I write this, because so many of these things my husband and I would have loved to have done and had the memories doing them. It was too hard at the time for us to think straight." (Stillbirth).

Many respondents living in rural areas noted the lack of availability of resources and knowledgeable care givers in their communities. In these cases, transportation and the need for child care prevented families from accessing much needed supports. In many locations, even when resources were available, families encountered barriers when trying to access these resources. Some reported that they were given outdated pamphlets and phone numbers while others were never offered information or support or counseling options. Follow-up by healthcare professionals was also cited as a concern, with one parent noting that, "I had called the social worker and left a message but nothing was returned. I felt as though I was left out in the dust." (Stillbirth) The availability of spiritual care and legal advice was also noted as an important element of support that was often unavailable. One person who was unable to access spiritual care reported that nothing was offered, stating, "I needed that support, but it wasn't offered in any booklet, or pamphlet ... the chaplain wasn't asked to come, and there was no pastoral care information at all." (Miscarriage/early loss). 


\section{Making a difference}

Respondents indicated that the actions of healthcare professionals could make a positive and lasting difference in the experience of loss. These actions consisted mostly of small gestures from providers in a range of disciplines that were integrated into care. One parent noted,

"The care I received in hospital was amazing. The nurses were there to talk, help us after he was born and the following day with pictures and allowing us to spend more time with our son before I had to leave." (Stillbirth).

It was often the little things that made a difference, as in the case of one person who explained that,

"I was thankful for my nurse who came in after to do bloodwork because she took two minutes to give me a hug, a cloth to clean my face, some clean pads and said 'I'm so sorry for your loss'. Then she did what she needed to do. A little compassion goes a long way." (Miscarriage/early loss).

Another noted,

"Some of the nurses for the quick minute I got to speak to them shared their experiences and it happens so often and yet no one talks about it. It was nice for them to share and it made me feel better."

(Miscarriage/early loss).

Respondents appreciated any contact from care providers that let them know they had some understanding of what they were experiencing. For example, one person said,

"I was so impressed that my family doctor called me directly over the phone to see how I was doing...

(She) had never called me before but she clearly understood that this situation was different and that I would need someone to talk to and benefit from hearing from her directly so that I could ask questions." (Miscarriage/early loss).

Another reported that, "My midwife...made sure that I understood the process, she made sure I kept my baby overnight and then she followed up with me weekly for 6 weeks afterward." (Stillbirth).

The power to make a positive difference in the experience of loss was evident in one person's story who had had a Caesarean section and was encouraged to be involved in planning her baby's funeral. "It was therapeutic...my husband and I both got to see our child leave the morgue. I always have appreciated that our wish to do this was taken seriously. For that I am forever grateful." (Neonatal death).

\section{Discussion}

This study reports on families' experiences of all types of pregnancy and infant loss. Specific areas of focus for this discussion include stigma and the meaning of loss, the context of care, and supports.

\section{Stigma and the meaning of loss}

Consistent with other studies [19, 40, 42-45], respondents described experiences of disenfranchised grief, whereby losses are not legitimized by health and service professionals, families, and communities, as a source of distress. The insensitive language of loss, for example, the use of 'fetus' or 'abortion' by healthcare professionals, contributed to a sense of isolation. Our findings continue to shed light on the difficulties many families faced after pregnancy or infant loss, and how families live in the world after this experience - as 'othered'. This study highlights the commonality of the experience of isolation, regardless of the time and type of loss, and the desire to have the meaning of loss recognized by healthcare professionals. If healthcare professionals minimize or misunderstand the impact of loss, even unintentionally, they may be less likely to recognize families' needs for anticipatory guidance and referrals to available resources and supports.

Our findings surrounding the frequent impact of stigma and silence surrounding pregnancy and infant loss has also been described in the literature $[5,12,14$, $22,24,27,41,45-50]$. As stigmatization can be enacted by thoughtlessness or insensitivity, paying attention to the words used and personal biases around loss, which have the potential to either intensify suffering or affirm the meaning of the loss for families, may be a means by which professionals can avoid perpetuating feelings of stigma and isolation [40,51]. Understanding the extent to which stigmatization impacts grief and healing should be a priority in care provision and future research.

\section{Healthcare professionals and the context of care}

Our finding that families did not always receive the quality of care that they desired has been reported elsewhere $[2,4,7,8,17,20,25,26,28,29,52-56]$. Bereavement care is challenging and difficult work for care providers, who are often managing competing demands and resource limitations $[5,57]$. A lack of clear clinical guidelines may complicate the provision of skilled and compassionate care, as may a lack of formal education for most professionals [15, 20, 28, 46, 54, 58-61]. Individual risk factors such as lack of experience, personal feelings of inadequacy, and frequent exposure to loss may cause some professionals to emotionally disengage 
and distance themselves from care. There is a need to build supportive and responsive communities of practice for professionals who witness the suffering of families in their everyday practice. As identified elsewhere [15, 21], our findings support the need to develop bereavement practice guidelines or care pathways that may help to minimize the wide variation in care that families receive from the healthcare system and healthcare professionals, both at the time of and after the loss. At the same time, families also value personalized supports.

While the environment of care influenced the experience of loss, some families described professionals who were able to overcome inhospitable contexts and have a positive impact on the loss experience, regardless of their workplace setting. While the lack of resources and time may be constraining factors, the findings in our study, supported elsewhere, suggest that families placed importance on a provider's caring manner and a willingness to communicate [21, 56, 62]. Despite ongoing challenges, professionals can make a positive impact with the care they provide.

Consistent with previous studies $[10,14,15,20,21,28$, $56,63]$, communication failures created barriers to acceptable care for families. Families in our survey indicated that improvements in care could be made by providing information and explanations, discharge and follow-up instructions, and through discussions about available supports. Information and supports should be culturally sensitive and available in multiple languages. Opportunities exist to better develop the communication skills of healthcare professionals. Knowledge translation strategies for moving feedback about quality care into practice is an area for future research.

\section{Support}

Although families accessed different types of care at multiple points during their loss, almost half were never told about available supports. Despite evidence that peer support is valued by families, [1, 20, 21, 26, 44, 64] we found that many families were still not told about or able to access peer support services. Echoing other literature, [65-68] families indicated peer support was helpful because it reduced isolation, allowed people to share about their babies and experiences, and provided opportunities to listen to others talk about their babies. As discussed elsewhere [56], partners, family members, and healthcare professionals were identified as sources of support. When interacting with families, we encourage professionals to assume that a discussion about available resources and supports has not already happened, and to initiate this conversation.

Families in our survey identified support needs that continued long past the loss event. An unanticipated finding was how often families reported that their needs for support changed over time, indicating a need for diverse types of support to meet the ongoing needs of families. This has implications for the anticipatory guidance provided by healthcare professionals and for program planning to ensure community resources reflect changing needs.

Our findings align with the work of others that have highlighted the need to invest in better supports for families, as well as the need to clearly identify supports to families $[14,19,22,26,45,53,55,69]$. We are concerned about the long-term implications when the need for support is not recognized, families are not told about supports, and access to supports is limited. Attempts to better quantify and inform health policy about the tangible and intangible costs of perinatal loss, such as impact on the health of the partner, financial stress, and work-related lost productivity, have been undertaken by several researchers $[5,6,13,70-74]$. More research into the long-term consequences of not getting support following loss for the individual, their partner, and the community is needed. The development and provision of family-identified supports should be a continued focus of government, health systems, and communities.

\section{Strengths and limitations}

This study collected information via an internet survey, which had the potential limitations of self-selection bias, sampling bias, and coverage bias [75]. Most respondents to our survey would have seen the invitation to participate in two main online locations where they were already actively involved, and thus already connected to the perinatal bereavement community. People without online access were excluded from this study, as were those who could not complete a survey in English. Limitations of this study also included a lack of diversity in race, gender, and economic backgrounds of the individuals who participated in the survey, which limits the generalizability of our findings. While thematic analysis of the open-ended question facilitated understanding of the experiences of families in their own words, having only one open-ended question also limited the extent to which we were able to more deeply understand, qualitatively, the lived experience of perinatal loss [35].

In our analysis, we focused on reporting responses that clearly indicated that good, quality, and respectful care was received, but acknowledge that this expectation and interpretation for acceptable provision of healthcare may be debated. For example, when asked if at the time of their loss they felt treated with kindness and respect by the healthcare provider(s), we highlighted when respondents selected 'yes - definitely', and did not highlight responses of 'yes - somewhat' or 'no', as we perceived both responses to indicate a gap or need for improvement. As reported elsewhere $[19,21,53,56]$, several respondents 
indicated that during their loss, kind, skilled, and respectful care was inconsistent, sometimes depending on the professional or environment of care. We acknowledge that fixed survey questions result in a loss of ability to capture subtleties and to address variations in care that exist in the 'real world'.

Strengths of this study were the large number of participants for qualitative data collection and that this was the first study of its kind surveying a large population of families experiencing all types of pregnancy and infant loss to be conducted in Canada. The use of qualitative and quantitative data was a strength that contributes to our understanding of the needs of this population.

\section{Conclusion}

This study has the potential to raise awareness and provide strategies to improve care for families experiencing the loss of a pregnancy or the loss of an infant. As one participant expressed, "Our experiences do not disappear or reset with a new health concern or pregnancy. Loss parents need to be treated with empathy and compassion always so they can trust their healthcare professionals the next time they are patients".

Quality in healthcare is shaped by the experiences and engagement of patients, families, caregivers, and professionals. Families' responses indicated a clear need of and directions to improve care for those experiencing the loss of a pregnancy or the death of an infant in Ontario. Healthcare professionals can make a positive difference in how loss is experienced by recognizing the impact of the loss, providing compassionate care through the use of sensitive language and physical supports, minimizing uncertainty and isolation, and by sensitively working within physical environments often not designed for experiences of loss. Access to specialized education should be prioritized for professionals providing services and care to this population.

\section{Abbreviations}

D\&C: Dilation and curettage; EMS: Emergency Medical Services;

ER: Emergency Room; GP: General practitioner; HCP: Healthcare providers; LGBTQ2S: Lesbian, gay, bisexual, transgender, queer, 2-Spirit; N: Population size; n: Sample size; PAIL Network: Pregnancy and Infant Loss Network

\section{Acknowledgements}

We warmly acknowledge the families who participated in the survey and shared their stories, experiences, and thoughts. We would also like to acknowledge the work of Rukhsar Jaffer for her assistance in the preparation of the manuscript.

\section{Funding}

Not Applicable.

\section{Availability of data and materials}

The datasets used and/or analyzed during the current study are available from the corresponding author upon request.

\section{Authors' contributions}

JW conceptualized the study and led the quantitative analysis and manuscript development. AS conducted the qualitative analysis and wrote the qualitative section of the manuscript. MF developed the online survey and participated in the quantitative analysis and manuscript development. $M L$ reviewed the online survey, supported the distribution of the survey, and reviewed drafts of the analysis and manuscript development from a broader provincial perspective of pregnancy and infant loss. All authors have read and approved the complete version of this manuscript.

Ethics approval and consent to participate

Ethics approval was received from the Sunnybrook Health Sciences Centre Research Ethics Board (Approval Number: 443-2016).

Informed consent was implied through independent completion and submission of the survey.

\section{Consent for publication \\ Not Applicable.}

\section{Competing interests}

The authors declare that they have no competing interests.

\section{Publisher's Note}

Springer Nature remains neutral with regard to jurisdictional claims in published maps and institutional affiliations.

Received: 10 August 2018 Accepted: 27 March 2019

Published online: 16 April 2019

\section{References}

1. Murphy S, Cacciatore J. The psychological, social, and economic impact of stillbirth on families. Semin Fetal Neonatal Med. 2017;22(3):129-34.

2. Lok $I H$, Neugebauer R. Psychological morbidity following miscarriage. Best Pract Res Clin Obstet Gynaecol. 2007;21(2):229-47.

3. Christiansen DM, Elklit A, Olff M. Parents bereaved by infant death: PTSD symptoms up to 18 years after the loss. Gen Hosp Psychiatry. 2013;35(6):605-11.

4. Cacciatore J. Psychological effects of stillbirth. Semin Fetal Neonatal Med. 2013:18(2):76-82.

5. Heazell AE, Siassakos D, Blencowe H, Burden C, Bhutta ZA, Cacciatore J, et al. Stillbirths: economic and psychosocial consequences. Lancet. 2016; 387(10018):604-16.

6. Ogwulu CB, Jackson $L$, Heazell $A E$, Roberts TE. Exploring the intangible economic costs of stillbirth. BMC Pregnancy Childbirth. 2015;15:188.

7. Flenady V, Boyle F, Koopmans L, Wilson T, Stones W, Cacciatore J. Meeting the needs of parents after a stillbirth or neonatal death. BJOG. 2014; 121(Suppl 4):137-40.

8. Brooten D, Youngblut JM, Seagrave L, Caicedo C, Hawthorne D, Hidalgo I, et al. Parent's perceptions of health care providers actions around child ICU death: what helped, what did not. Am J Hosp Palliat Care. 2013;30(1):40-9.

9. Gravensteen IK, Jacobsen EM, Sandset PM, Helgadottir LB, Rådestad I, Sandvik $L$, et al. Anxiety, depression and relationship satisfaction in the pregnancy following stillbirth and after the birth of a live-born baby: a prospective study. BMC Pregnancy Childbirth. 2018;18(1):41.

10. Nuzum D, Meaney S, O'Donoghue K. The spiritual and theological challenges of stillbirth for bereaved parents. J Relig Health. 2017;56(3): 1081-95.

11. Gold KJ, Sen A, Leon I. Whose fault is it anyway? Guilt, blame, and death attribution by mothers after stillbirth or infant death. IIIn Crisis Loss. 2018; 26(1):40-57

12. Goldstein RD, Lederman RI, Lichtenthal WG, Morris SE, Human M, Elliott AJ, Tobacco D, Angal J, Odendaal H, Kinney HC, Prigerson HG, for the PASS Network. The grief of mothers after the sudden unexpected death of their infants. Pediatrics. 2018;141(5):e20173651. https://doi.org/10.1542/peds.20173651

13. Campbell HE, Kurinczuk JJ, Heazell A, Leal J, Rivero-Arias O. Healthcare and wider societal implications of stillbirth: a population-based cost-of-illness study. BJOG. 2018;125(2):108-17.

14. Fockler ME, Ladhani NNN, Watson J, Barrett JFR. Pregnancy subsequent to stillbirth: medical and psychosocial aspects of care. Semin Fetal Neonatal Med. 2017;22(3):186-92. 
15. Wojcieszek AM, Boyle FM, Belizán JM, Cassidy J, Cassidy P, Erwich JJHM, Farrales L, Gross MM, Heazell AEP, Leisher SH, Mills T, Murphy M, Pettersson K, Ravaldi C, Ruidiaz J, Siassakos D, Silver RM, Storey C, Vannacci A, Middleton P, Ellwood D, Flenady V. Care in subsequent pregnancies following stillbirth: an international survey of parents. BJOG. 2018;125(2):193201. ISSN 1470-0328.

16. Brooten D, Youngblut JM, Hannan J, Caicedo C, Roche R, Malkawi F. Infant and child deaths: parent concerns about subsequent pregnancies. J Am Assoc Nurse Pract. 2015;27(12):690-7.

17. Christiansen DM. Posttraumatic stress disorder in parents following infant death: a systematic review. Clin Psychol Rev. 2017:51:60-74.

18. Endo K, Yonemoto N, Yamada M. Interventions for bereaved parents following a child's death: a systematic review. Palliat Med. 2015;29(7): 590-604.

19. Watson M, Jewell V, Smith S. Journey Interrupted: A Phenomenological Exploration of Miscarriage. Open J Occup Ther. 2018;6(3):7.

20. Mills TA, Ricklesford C, Cooke A, Heazell AE, Whitworth M, Lavender T. Parents' experiences and expectations of care in pregnancy after stillbirth or neonatal death: a metasynthesis. BJOG. 2014;121(8):943-50.

21. Mills TA, Ricklesford C, Heazell AE, Cooke A, Lavender T. Marvellous to mediocre: findings of national survey of UK practice and provision of care in pregnancies after stillbirth or neonatal death. BMC Pregnancy Childbirth. 2016;16:101-016 0891-2

22. Burden C, Bradley S, Storey C, Ellis A, Heazell AE, Downe S, et al. From grief, guilt pain and stigma to hope and pride - a systematic review and metaanalysis of mixed-method research of the psychosocial impact of stillbirth. BMC Pregnancy Childbirth. 2016;16:9-016 0800-8.

23. Meaney S, Everard CM, Gallagher S, O'Donoghue K. Parents' concerns about future pregnancy after stillbirth: a qualitative study. Health Expect. 2017; 20(4):555-62. ISSN 1369-6513.

24. O'Leary J, Warland J, Parker L. Bereaved parents' perception of the grandparents' reactions to perinatal loss and the pregnancy that follows. J Fam Nurs. 2011;17(3):330-56.

25. Côté-Arsenault D, Bidlack D, Humm A. Women's emotions and concerns during pregnancy following perinatal loss. MCN Am J Matern Child Nurs. 2001;26(3):128-34

26. Ellis A, Chebsey C, Storey C, Bradley S, Jackson S, Flenady V, et al. Systematic review to understand and improve care after stillbirth: a review of parents' and healthcare professionals' experiences. BMC Pregnancy Childbirth. 2016;16:16.

27. Armstrong DS. Impact of prior perinatal loss on subsequent pregnancies. J Obstet Gynecol Neonatal Nurs. 2004;33(6):765-73.

28. Punches B, Johnson KD, Acquavita SP, Felblinger DM, Gillespie GL. Patient perspectives of pregnancy loss in the emergency department. Int Emerg Nurs. 2019;43:61-6. ISSN 1755-599X.

29. Gijzen S, L'Hoir MP, Boere-Boonekamp MM, Need A. How do parents experience support after the death of their child? BMC Pediatr. 2016;16(1):204

30. Live births and fetal deaths (stillbirths), by type of birth (single or multiple). Statistics Canada Table 13-10-0428-01, 2018. Statistics Canada; 2018.https:// www150.statcan.gc.ca/t1/tbl1/en/tv.action?pid=1310042801. Accessed 25 June 2018.

31. Bierman A, Angus J, Ahmad F, Degani N, Vahabi M, Glazier R, et al. Access to Health Care Services. Toronto2009. Available from: http://www. powerstudy.ca/. Accessed 14 July 2018.

32. Northwest Health Alliance. Conditions related to Threatened/Missed/ Spontaneous/Social Abortion Cases (CIHI case mix groups 548-551) in Ontario from April 1, 2016 to March 31, 2017. Ontario Ministry of Health and Long-Term Care: IntelliHEALTH ONTARIO; 2018.

33. Infant mortality, by birth weight. In: Canada S, editor. Statistics Canada; 2018. https://www150.statcan.gc.ca/t1/tbl1/en/tv.action?pid=1310036801. Accessed 25 June 2018.

34. Bill 141, Pregnancy and Infant Loss Awareness, Research and Care Act, 2015. Legislative Assembly of the Province of Ontario; Ministry of Health and Long-Term Care. 2015. https://www.ola.org/en/legislative-business/bills/ parliament-41/session-1/bill-141. Accessed 20 Nov 2016.

35. Frey J. Open ended question. In: Lewis-Beck M, Bryman A, Ruting Liao T, editors. The Sage Encyclopedia of Social Science Research Methods. http:// sk.sagepub.com/reference/socialscience. Accessed 10 Apr 2018.

36. O'Cathain A, Thomas KJ. "Any other comments?" open questions on questionnaires - a bane or a bonus to research? BMC Med Res Methodol. $2004 ; 4: 25$
37. SurveyMonkey 1999-2018 [Available from: https://www.surveymonkey.com/

38. Thomas DR. A general inductive approach for analyzing qualitative evaluation data. Am J Eval. 2006;27(2):237-46. ISSN 1098-2140.

39. Nowell L, Norris J, White D, Moules N. Thematic analysis: striving to meet the trustworthiness criteria. Int J Qual Methods. 2017;16(1-3):1-13.

40. Cook RJ, Dickens BM. Reducing stigma in reproductive health. Int J Gynaecol Obstet. 2014;125(1):89-92.

41. Brierley-Jones L, Crawley R, Lomax S, Ayers S. Stillbirth and stigma: the spoiling and repair of multiple social identities. Omega (Westport). 2014; 70(2):143-68.

42. Lang A, Fleiszer AR, Duhamel F, Sword W, Gilbert KR, Corsini-Munt S. Perinatal loss and parental grief: the challenge of ambiguity and disenfranchised grief. Omega (Westport). 2011;63(2):183-96.

43. Cox A, Wainwright $L$. The experience of parents who lose a baby of a multiple birth during the neonatal period - a literature review. J Neonatal Nurs. 2014;21(3):104-13.

44. Sawicka M. Searching for a narrative of loss: interactional ordering of ambiguous grief. Symb Interact. 2016;40(2):229-46.

45. Markin RD, Zilcha-Mano S. Cultural processes in psychotherapy for perinatal loss: breaking the cultural taboo against perinatal grief. Psychotherapy (Chic). 2018:55(1):20-6.

46. de Bernis L, Kinney MV, Stones W, Ten Hoope-Bender P, Vivio D, Leisher SH, et al. Stillbirths: ending preventable deaths by 2030. Lancet. 2016; 387(10019):703-16.

47. Lafarge C, Mitchell K, Fox P. Termination of pregnancy for fetal abnormality: a meta-ethnography of women's experiences. Reprod Health Matters. 2014; 22(44):191-201.

48. Bommaraju A, Kavanaugh ML, Hou MY, Bessett D. Situating stigma in stratified reproduction: abortion stigma and miscarriage stigma as barriers to reproductive healthcare. Sex Reprod Healthc. 2016;10:62-9.

49. Haws R, Mashasi I, Mrisho M, Armstrong Schellenberg J, Darmstadt G, Winch $P$. "These are not good things for other people to know": how rural Tanzanian women's experiences of pregnancy loss and early neonatal death may impact survey data quality. Soc Sci Med. 2010;71(10):1764-72.

50. Yang LH, Kleinman A, Link BG, Phelan JC, Lee S, Good B. Culture and stigma: adding moral experience to stigma theory. Soc Sci Med. 2007:64(7):1524-35.

51. Jonas-Simpson C, McMahon E. The language of loss when a baby dies prior to birth: cocreating human experience. Nurs Sci Q. 2005;18(2):124-30.

52. Wright PM. Childbirth education for parents experiencing pregnancy after perinatal loss. J Perinat Educ. 2005;14(4):9-15.

53. Garstang J, Griffiths F, Sidebotham P. What do bereaved parents want from professionals after the sudden death of their child: a systematic review of the literature. BMC Pediatr. 2014;14:269.

54. Aiyelaagbe E, Scott RE, Holmes V, Lane E, Heazell AEP. Assessing the quality of bereavement care after perinatal death: development and piloting of a questionnaire to assess parents' experiences. J Obstet Gynaecol. 2017;37(7): 931-6.

55. Rowlands I, Lee C. 'The silence was deafening': social and health service support after miscarriage. J Reprod Infant Psychol. 2010;28(3):274-86.

56. Redshaw M, Rowe R, Henderson J. Listening to parents after stillbirth or the death of their baby after birth. Oxford: National Perinatal Epidemiology Unit, University of Oxford; 2014

57. Peters MD, Lisy K, Riitano D, Jordan Z, Aromataris E. Caring for families experiencing stillbirth: evidence-based guidance for maternity care providers. Women Birth. 2015;28(4):272-8.

58. Heazell AE, Whitworth MK, Whitcombe J, Glover SW, Bevan C, Brewin J, et al. Research priorities for stillbirth: process overview and results from UK stillbirth priority setting partnership. Ultrasound Obstet Gynecol. 2015;46(6): $641-7$.

59. Flenady V, Wojcieszek AM, Middleton P, Ellwood D, Erwich JJ, Coory M, et al Stillbirths: recall to action in high-income countries. Lancet. 2016;387(10019): 691-702.

60. Ravaldi C, Levi M, Angeli E, Romeo G, Biffino M, Bonaiuti R, et al. Stillbirth and perinatal care: are professionals trained to address parents' needs? Midwifery. 2018;64:53-9

61. Siassakos D, Jackson S, Gleeson K, Chebsey C, Ellis A, Storey C, et al. All bereaved parents are entitled to good care after stillbirth: a mixed-methods multicentre study (INSIGHT). BJOG. 2018;125(2):160-70.

62. Grocott A, McSherry W. The patient experience: informing practice through identification of meaningful communication from the patient's perspective. Healthcare (Basel). 2018;6(1):26. ISSN 2227-9032. 
63. Ladhani NNN, Fockler ME, Stephens L, Barrett JFR, Hezaell AEP. No. 369 Management of pregnancy subsequent to stillbirth. J Obstet Gynaecol Can. 2018:40(12):1669-83.

64. DeBackere KJ, Hill PD, Kavanaugh KL. The parental experience of pregnancy after perinatal loss. J Obstetric Gynecol Neonatal Nurs. 2008;37(5):525-37.

65. Davidson D, Letherby G. Griefwork online: perinatal loss, lifecourse disruption and online support. Hum Fertil (Camb). 2014;17(3):214-7.

66. Aho AL, Paavilainen E, Kaunonen M. Mothers' experiences of peer support via an internet discussion forum after the death of a child. Scand J Caring Sci. 2012;26(3):417-26,

67. Carlson R, Lammert C, O'Leary J. The evolution of group and online support for families who have experienced perinatal of neonatal loss. Illn Crisis Loss. 2012;20(3):275-93.

68. Gold KJ, Boggs ME, Mugisha E, Palladino CL. Internet message boards for pregnancy loss: who's on-line and why? Womens Health Issues. 2012;22(1):e67-72.

69. Séjourné N, Callahan S, Chabrol H. Support following miscarriage: what women want. J Reprod Infant Psychol. 2010;28(4):403-11.

70. Mistry $\mathrm{H}$, Heazell AE, Vincent $\mathrm{O}$, Roberts T. A structured review and exploration of the healthcare costs associated with stillbirth and a subsequent pregnancy in England and Wales. BMC Pregnancy Childbirth. 2013;13:236

71. Warland J, O'Leary J, McCutcheon H, Williamson V. Parenting paradox: parenting after infant loss. Midwifery. 2011;27(5):e163-9.

72. Warland J, O'Leary J, McCutcheon H. Born after infant loss: the experiences of subsequent children. Midwifery. 2011;27(5):628-33.

73. Markin RD. What clinicians miss about miscarriages: clinical errors in the treatment of early term perinatal loss. Psychotherapy (Chic). 2016;53(3):347-53.

74. Ateva E, Blencowe H, Castillo T, Dev A, Farmer M, Kinney M, et al. Every woman, every Child's 'Progress in Partnership' for stillbirths: a commentary by the stillbirth advocacy working group. BJOG. 2018;125(9):1058-60.

75. Aday LA, Cornelius L. Designing and Conducting Health Surveys - A Comprehensive Guide. Third ed. San Francisco: Jossey-Bass; 2006.

Ready to submit your research? Choose BMC and benefit from:

- fast, convenient online submission

- thorough peer review by experienced researchers in your field

- rapid publication on acceptance

- support for research data, including large and complex data types

- gold Open Access which fosters wider collaboration and increased citations

- maximum visibility for your research: over $100 \mathrm{M}$ website views per year

At $\mathrm{BMC}$, research is always in progress.

Learn more biomedcentral.com/submissions 